\title{
A percepção dos jogos de simulação como técnica de aprendizagem
}

\author{
The perceptions of simulations games as learning technique
}

\author{
Cristina Camila Teles Saldanha ${ }^{1}$ \\ Luana Jéssica Oliveira Carmo ${ }^{2}$ \\ Carolina Calazans Lopes ${ }^{3}$ \\ Uajará Pessoa Araujo 4
}

\section{Resumo}

A preocupação em utilizar ferramentas de aprendizagem no meio acadêmico aumenta quando se trata dos cursos de Administração. A aproximação do aluno à realidade empresarial consiste em um desafio dentre as aulas expositivas. Nesse intuito, a Empresa Simulada surge como uma ferramenta atraente ao dotar os alunos do poder de decisão. Esse artigo tem como objetivo investigar a percepção de alunos e consultores sobre a contribuição da Empresa Simulada para a aprendizagem de práticas administrativas. Trata-se de um estudo de caso desenvolvido com uma turma do $5^{\circ}$ período da graduação em Administração de Empresas de uma entidade federal. Os dados empíricos foram coletados por meio de observação participante e grupos focais realizados ao final do jogo, suplementados pela aplicação da escala Learning Style Inventory (LSI) para caracterização dos alunos em relação ao seu estilo predominante de aprendizagem. Os resultados se apresentaram alinhados à teoria no que diz respeito à aproximação da Empresa Simulada à realidade, e da importância da utilização da ferramenta como forma de envolver os alunos em solucionar problemas que vão deparar em sua vida profissional.

Palavras-Chave: Empresa Simulada. Aprendizagem. Estilos de Aprendizagem. Aprendizagem Vivencial.

\begin{abstract}
The concern in using learning tools in academia increases when it comes to management courses. The approximation of the student to the business reality is a challenge in lectures. To that end, the Simulated Company emerges as an attractive tool to give students the power of decision. This article aims to investigate the perception of management undergraduate students and consultants about the contribution of the business simulation to the learning of administrative practices. This is a case study that was developed with a group of 5th period from course of the Business Administration of a federal entity involved in activities related to simulation. Empirical data were collected participant observation during the decisions of the groups during the Simulated Company discipline and focus groups that took place at the end of the game supplemented by the application range Learning Style Inventory (LSI) for characterization of students in relation to their predominant style of learning. The results were aligned to the theory concerning the approximation of Simulated Company to reality, and the importance of using the tool as a way to engage students in solving problems that will come across in your professional life.
\end{abstract}

Keywords: Simulated Company. Learning. Learning Styles. Experiential learning.

\footnotetext{
Mestranda em Administração Pública pela Fundação João Pinheiro. Brasil. Afiliação: Centro Federal de Educação Tecnológica de Minas Gerais - CEFET- MG. Lattes: http://lattes.cnpq.br/9806559441955152 Email: cristina.c.t.saldanha@gmail.com

2 Mestranda em Adminitração pelo Centro Federal de Educação Tecnológica de Minas Gerais - CEFET-MG. Brasil. Afiliação: CEFET-MG. Lattes: http://lattes.cnpq.br/0893740952843691 Email: luanajeoli@gmail.com

3 Mestranda em Adminitração pelo Centro Federal de Educação Tecnológica de Minas Gerais - CEFET-MG. Brasil. Afiliação: CEFET-MG. Lattes: http://lattes.cnpq.br/1250305624942898 Email: lopescalazanscarolina@msn.com

4 Doutor em Engenharia de Produção pela Escola de Engenharia de São Carlos - USP. Doutor em Administração pela Universidade Federal de Lavras - UFLA. Brasil, Afiliação: Centro Federal de Educação Tecnológica de Minas Gerais - CEFET- MG. Lattes: http://lattes.cnpq. br/3898285928077336 Email: uajara@yahoo.com.br
} 


\section{Introdução}

Ao longo dos últimos anos, diversas técnicas de ensino têm sido adotadas pelas instituições educacionais na busca da transmissão do conhecimento. Para Motta, Armond-de-Melo e Paixão (2012), alguns projetos tais como o Programa de Capacitação Docente em Administração (PCDA), pertencente à Associação Nacional de Pós-graduação e Pesquisa em Administração (ANPAD), demonstram a preocupação e a inquietação dos pesquisadores e professores com as abordagens atuais de ensino e aprendizagem em Administração.

Santos et al. (2014) enfatizam que as produções acadêmicas de Administração destacam a relevância do aprendizado prático para o entendimento do processo gerencial. Nessa lógica, as técnicas de simulação por meio de jogos têm sido empregadas com maior frequência. Nagamatsu, Fedichina e Gozzi (2006) afirmam que os jogos simulados permitem ao estudante a oportunidade de participar de simulações relacionadas à tomada de decisões, trabalho em equipe, delimitação de estratégias, negociação e desenvolvimento de habilidades de liderança.

Santos et al. (2014) ainda mencionam que os jogos simulados foram considerados instrumentos de aprendizagem no ano de 1957, nos Estados Unidos. No Brasil, esta técnica começou a ser utilizada na década de 1970, sendo conhecida como uma metodologia de complementação ao ensino/aprendizagem (SANTOS et al., 2014). Sauaia (2006) ressalta que o recurso de utilização de jogos amplifica as bases do ensino tradicional, tornando possível ao estudante o aprendizado por meio da prática.

Nesta perspectiva, os cursos de graduação utilizam de recursos vivenciais, contribuindo para a formação do aluno no que tange às práticas administrativas. Para Rodrigues e Souza (2001), a simulação é aplicada no ensino superior com o intuito de reproduzir o ambiente e o comportamento do mercado de trabalho, experiência que os estudantes provavelmente não teriam acesso antes de se formarem. Os autores ainda ponderam que existe a preocupação referente à aprendizagem prática devido à importância do desenvolvimento de competências vinculadas à tomada de decisão.

Sauaia (2006) afirma que os jogos simulados oferecem uma experiência vivencial aos alunos, ao aproximá-los de fatos corriqueiros das organizações. No entanto, é necessário analisar se esta aprendizagem é percebida pelos alunos como um processo que de fato permite o contato com a realidade do mercado de trabalho. Dessa maneira, tem-se a seguinte pergunta de pesquisa: Qual é a percepção dos alunos do curso de Administração e dos consultores sobre a contribuição da disciplina Empresa Simulada para a aprendizagem de práticas administrativas? Portanto, o artigo possui como objetivo geral investigar a percepção de alunos e consultores sobre a contribuição da Empresa Simulada para a aprendizagem de práticas administrativas.

Para esse estudo foram realizadas observações participantes durante as aulas pelos chamados "consultores" - alunos de mestrado da mesma instituição de ensino. Em vez de simples moderadores para acompanhar o rendimento dos alunos durante os jogos, os consultores tiveram o poder de decisão quanto à intervenção ou não nas dinâmicas dos jogos dos graduandos.

Para captar as percepções dos alunos e consultores em relação a dinâmica das simulações, foram realizados grupos focais ao final da disciplina. De forma complementar foi aplicado o instrumento "Inventário de Estilos de Aprendizagem" (Learning Style Inventory - LSI), elaborado por David Kolb (1984), com o intuito de identificar os estilos de aprendizagem dos alunos da graduação. A contribuição do LSI foi útil na descrição dos comportamentos dos estudantes perante o aprendizado por formatos presenciais.

A relevância do estudo se aclara ao evidenciar, sob a ótica dos alunos e dos consultores, o impacto da utilização de uma ferramenta de ensino que distancia da tradicional aula expositiva em que o professor é o protagonista. Na empresa simulada, o aluno torna-se o ator principal ao ganhar o poder da tomada de decisão, aproximando seu aprendizado da realidade. Nesse trabalho contou-se com a participação dos consultores, um adicional ainda não abordado em outros trabalhos publicados. Em suma, a contribuição do trabalho é apresentar a percepção dos alunos e consultores em relação à dinâmica da Empresa Simulada sob o ponto de vista prático. 
Esse trabalho tem, portanto, a intenção de reduzir a lacuna referente aos estudos relacionados ao aprendizado em Empresa Simulada ao analisar a percepção de alunos e dos consultores, uma vez que os trabalhos já existentes ainda são incipientes quanto ao impacto dessa ferramenta para a aprendizagem na formação administrativa. Em comparação a estudos anteriores recentes sobre a temática no Brasil, vide o trabalho de Motta, Armond-De-Melo, e Paixão (2012), que verificaram os Discursos Sociais Coletivos de 72 alunos dos cursos de graduação e de especialização em Administração sobre as percepções desses para a técnica de jogos de empresas.

Além disso, o presente trabalho traz um adicional devido ao distinto formato de observação participante. Os estilos de aprendizagem foram utilizados na formação das equipes no estudo de Motta, Armond-De-Melo, e Paixão (2012), enquanto nessa investigação, o inventário de Kolb (1984) foi mensurado após a prática vivencial, o que colabora para a não-intencionalidade da pesquisa haja vista que os alunos escolhiam os próprios membros de grupos e também houve rotatividade entre alguns integrantes durante as rodadas.

\section{Referencial Teórico}

\subsection{A Empresa Simulada}

Os jogos de empresas não são uma ferramenta recente. Acredita-se que surgiram na China, com os jogos de guerra por volta de 3.000 anos a.C. Ao evoluir para os jogos empresariais, os "jogos de guerra" ganharam o nome de Top Management Decision Simulation, em sua primeira versão, em 1950, na América do Norte. O próprio nome já descreve o objetivo da simulação, que é de levar os participantes a tomarem decisões e acompanhar as consequências dessas. Desde sua chegada à América do Norte, o uso de jogos de simulação empresarial no meio acadêmico tem crescido. No Brasil, sua utilização iniciou em 1970, porém no país a ferramenta ainda não é tão largamente utilizada no meio acadêmico se comparada aos Estados Unidos. A simulação é uma técnica de aprendizagem baseada na resolução de problemas, em que os participantes ocupam cargos gerenciais em empresas fictícias e são levados a interagir com situações semelhantes as que são encontradas na realidade (SAUAIA, 2000). A ferramenta utilizada normalmente é informatizada, e gera relatórios aos participantes (SILVA; OLIVEIRA; MOTTA, 2013).

Silva, Oliveira e Motta (2013) afirmam que, nos jogos de empresas, os participantes são levados a tomar decisões de acordo com os cenários expostos e podem receber o feedback da simulação, o que segundo Sauaia (2000) é interessante por gerar ao aluno uma noção de responsabilidade, haja vista a demonstração das consequências dessas decisões. Na Empresa Simulada, ou Jogos de Empresas, ou ainda Jogos de Negócios, o participante pode falhar sem que tenha prejuízos reais, aprendendo assim com seus erros para evitá-los em sua atuação na realidade. O Quadro 1 apresenta de forma objetiva as características da Empresa Simulada.

\section{Quadro 1 - Características da Empresa Simulada}

\begin{tabular}{|l|l|}
\hline \multicolumn{1}{|c|}{ Característica } & \multicolumn{1}{c|}{ Empresa Simulada } \\
\hline Papel do Estudante & Autonomia no processo \\
\hline Papel do Professor & Auxiliar o processo \\
\hline Objetivo Educacional & Comportamento e atitude gerencial \\
\hline Qualificação do problema & Estimula o desenvolvimento do aluno \\
\hline Pontos Fortes & Interação pessoal entre os alunos por meio da prática vivencial \\
\hline Pontos fracos & $\begin{array}{l}\text { Necessidade de simuladores, normalmente envolve altos custos, } \\
\text { Dificuldade de avaliação da aprendizagem }\end{array}$ \\
\hline Desafios & $\begin{array}{l}\text { Necessita de grande interação multidisciplinar, Requer práticas } \\
\text { docentes inovadoras }\end{array}$ \\
\hline Oportunidades & Grande aceitação por parte de instituições de ensino \\
\hline Principal competência desenvolvida & Humana \\
\hline
\end{tabular}

Fonte: Adaptado de Motta e Armond-de-Melo (2008) 
Rosas e Sauaia (2009) afirmam que os jogos simulados são vivências de gestão, isto é, aproximam o participante da realidade de um gestor ao prover liberdade e autonomia para tomar decisões e observar as consequências. Dentro da sala de aula, o aluno ganha o papel ativo e o professor se torna o auxiliar do processo, distanciando das tradicionais aulas expositivas (SILVA; OLIVEIRA; MOTTA, 2013). Conforme Sauaia (2000), a utilização dos jogos de empresa proporciona aos participantes uma maior satisfação em detrimento de outros métodos de ensino, pois estariam mais envolvidos no processo de aprendizagem.

\subsection{Os Estilos de Aprendizagem}

A complexidade do ser humano faz com que ele não aprenda de forma igual aos demais. Para Oliveira (2012), cada aprendiz é único na forma como recebe, processa informações, lida com diferentes circunstâncias de aprendizagem, e como aprende de fato. Ou seja, o ato de aprender é um processo pessoal, observando-se que cada indivíduo aprende de determinada maneira. Os estudos sobre aprendizagem e seus estilos tiveram início no século $\mathrm{XX}$, com as pesquisas de psicólogos alemães que estudavam os tipos psicológicos.

Partindo desses estudos, surgiram várias formas de classificar essas diferenças de aprendizagem. Cerqueira (2000) cita Hunt e Sullivan (1974) e suas três concepções das diferenças de aprendizagem: estática, situacional e interacionista. A concepção estática considera que o indivíduo possui características relativamente estáveis e consistentes e as usa em qualquer cenário. Oposta a essa concepção, tem-se a situacional, em que o comportamento do indivíduo é determinado pelas variáveis ambientais de diferentes situações. Já na concepção interacionista, as características individuais e situacionais interagem, considerando aspectos que são inerentes ao indivíduo, assim como também ao contexto confrontado por ele.

A partir dessas classificações sobre as diferenças no aprendizado, surgem os estilos de aprendizagem. Os estilos de aprendizagem estão relacionados à forma como o indivíduo compreende a si mesmo, o mundo e a relação entre ambos. Kolb (1984) define os estilos de aprendizagem como um estado duradouro e estável, que derivam de configurações consistentes das trocas entre o indivíduo e seu meio ambiente. Para Felder e Silverman (1988), a aprendizagem reflete como o estudante aprende, dependendo ora do estilo de aprendizagem do aluno, ora pelo estilo do professor, dentro de uma sala de aula. Para os autores, os alunos aprendem de muitas maneiras: ao ver e ouvir, refletir e agir, pelo raciocínio lógico e intuitivo, memorização, visualização, analogias e construção de modelos matemáticos, é o que Silva, Oliveira e Motta (2013) consideram como o envolvimento do aluno em seu próprio processo de aprendizagem.

\subsubsection{A Aprendizagem Vivencial - O Modelo de Experiential learning de David Kolb}

A Empresa Simulada é considerada uma ferramenta de aprendizagem vivencial. Essa forma de aprendizagem passa por um ciclo contendo cinco etapas, caracterizadas por Baraúna e Montalvo (2012) como: vivência, relato, processamento, generalização e aplicação. A vivência é explicada pela interação proporcionada pela Empresa Simulada à realidade. O relato é o compartilhamento de experiências. No processamento, as características da experiência são identificadas; na generalização ocorre a ampliação do ensinamento para a realidade e por fim na aplicação o ensinamento é aplicado à situações práticas. Além disso, a aprendizagem vivencial "carrega" consigo a necessidade da liberdade. O aluno deve ser dotado de liberdade para tomar as decisões ao visualizar as consequências de suas ações e assim assumir uma postura de responsabilidade. Freire (2006) relata que a decisão é um processo responsável e a autonomia vai sendo adquirida gradualmente com as experiências.

Para Kolb (1984), a aprendizagem vivencial reconhece que os indivíduos aprendem de diferentes formas e respondem distintamente a um mesmo estímulo. Kolb (1984) compreende que a aprendizagem é mais bem concebida como um processo, não em termos de resultados a serem atingidos, como era a ótica da aprendizado mais tradicional. A partir da Teoria da Aprendizagem Experimental (Experiential Learning) que agrega teorias behavioristas e abordagens educacionais idealistas, ele afirma que as ideias não são fixas nem imutáveis, porém são formadas por meio das experiências (KOLB, 1984). 
Assim, o processo de aprendizagem envolve uma tensão entre a experiência vivida e a expectativa esperada de dada ação que produzirá um conhecimento (KOLB, 1984). Kolb (1984) considera que novos conhecimentos, habilidades e atitudes são adquiridos por quatro modos de aprendizagem experimental, portanto, o indivíduo necessita de quatro habilidades básicas para que seu aprendizado seja efetivo, de acordo com o Quadro 2.

Quadro 2 - Processo cíclico de aprendizagem de David Kolb

\begin{tabular}{|c|c|c|c|}
\hline $\begin{array}{c}\text { EXPERIÊNCIA } \\
\text { CONCRETA (EC) }\end{array}$ & $\begin{array}{l}\text { OBSERVAÇÃO } \\
\text { REFLEXIVA (OR) }\end{array}$ & $\begin{array}{l}\text { CONCEITUAÇÃO } \\
\text { ABSTRATA (CA) }\end{array}$ & $\begin{array}{c}\text { EXPERIMENTAÇÃO } \\
\text { ATIVA (EA) }\end{array}$ \\
\hline $\begin{array}{l}\text { Aprendizes devem ser } \\
\text { capazes de se envolverem } \\
\text { c o m p I e t a m e } \mathrm{n} \text { t e, } \\
\text { abertamente e sem vieses } \\
\text { à novas experiências. }\end{array}$ & $\begin{array}{l}\text { Aprendizes } \text { devem } \\
\text { ser capazes de refletir } \\
\text { sobre e observar suas } \\
\text { experiências a partir de } \\
\text { várias perspectivas }\end{array}$ & \begin{tabular}{lrr}
\multicolumn{2}{l}{ Aprendizes devem ser } \\
capazes de criar & conceitos \\
que integram & suas \\
observações de & teorias \\
lógicas. & & \\
\end{tabular} & $\begin{array}{l}\text { Aprendizes devem ser } \\
\text { capazes de usar suas } \\
\text { teorias para tomarem } \\
\text { decisões e resolver } \\
\text { problemas }\end{array}$ \\
\hline $\begin{array}{l}\text { Aprender por meio dos } \\
\text { sentimentos e do uso dos } \\
\text { sentidos. }\end{array}$ & Aprender observando. & $\begin{array}{l}\text { Aprender pensando. } \\
\text { Nessa etapa, a aprendizagem } \\
\text { compreende o uso da lógica } \\
\text { e das ideias. }\end{array}$ & $\begin{array}{l}\text { Aprender fazendo. A } \\
\text { aprendizagem toma } \\
\text { uma forma ativa. }\end{array}$ \\
\hline
\end{tabular}

Fonte: Adaptação de Kolb (1984, p. 30) tradução nossa.

Dessa forma, Kolb (1984) desenvolveu o denominado LSI, cuja interação cíclica entre essas quatro habilidades resulta em quatro dimensões de aprendizagem, ou estilos de aprendizagem: convergente, divergente, assimilador e acomodador, observado no Quadro 3:

\section{Quadro 3 - Descrição dos estilos de aprendizagem de David Kolb}

\begin{tabular}{|c|c|}
\hline $\begin{array}{l}\text { Divergente } \\
\text { Capacidades de } \\
\text { aprendizagem } \\
\text { dominantes: } \\
\text { Experiência Concreta } \\
\text { (EC) e Observação } \\
\text { Reflexiva (OR). }\end{array}$ & $\begin{array}{l}\text { As pessoas com este estilo de aprendizagem são os melhores em ver situações } \\
\text { concretas sob muitos pontos de vista diferentes. Ele é rotulado de "Divergência", porque } \\
\text { uma pessoa com ele executa melhor em situações que exigem geração de ideias, } \\
\text { como uma sessão de brainstorm. A pesquisa mostra que eles estão interessados em } \\
\text { pessoas, tendem a ser imaginativos e emocionais, têm amplos interesses culturais, e } \\
\text { tendem a especializar-se nas artes. Em situações de aprendizagem formal, pessoas } \\
\text { com o estilo Divergente preferem trabalhar em grupos, ouvindo com uma mente } \\
\text { aberta e receber feedback personalizado. }\end{array}$ \\
\hline $\begin{array}{l}\text { Assimilador } \\
\text { Capacidades de } \\
\text { aprendizagem } \\
\text { dominantes: } \\
\text { Conceitualização } \\
\text { abstrata (CA) e } \\
\text { Observação Reflexiva } \\
\text { (OR). }\end{array}$ & $\begin{array}{l}\text { As pessoas com este estilo de aprendizagem são os melhores em compreender uma } \\
\text { ampla gama de informações e coloca-las em forma concisa e lógica. Indivíduos com } \\
\text { um estilo Assimilador são menos focados em pessoas e mais interessados em ideias e } \\
\text { conceitos abstratos. Geralmente, as pessoas com este estilo acham mais importante } \\
\text { que uma teoria tenha solidez lógica de valor prático. O estilo de aprendizagem } \\
\text { Assimilador é importante para a eficácia nas carreiras de informação e científicas. } \\
\text { Em situações de aprendizagem formal, as pessoas com esse estilo preferem leituras, } \\
\text { palestras, explorando modelos analíticos, e ter tempo para pensar sobre as coisas. }\end{array}$ \\
\hline $\begin{array}{l}\text { Convergente } \\
\text { Capacidades de } \\
\text { aprendizagem } \\
\text { dominantes: } \\
\text { Conceitualização } \\
\text { abstrata (CA) e } \\
\text { Experimentação Ativa } \\
\text { (EA). }\end{array}$ & $\begin{array}{l}\text { As pessoas com este estilo de aprendizagem são melhores em encontrar usos } \\
\text { práticos para ideias e teorias. Eles têm a capacidade de resolver problemas e tomar } \\
\text { decisões com base em busca de soluções para questões ou problemas. Indivíduos } \\
\text { com um estilo de aprendizagem 'Convergente' preferem lidar com tarefas técnicas } \\
\text { e problemas, em vez de com as questões sociais e questões interpessoais. Essas } \\
\text { habilidades de aprendizagem são importantes para a eficácia nas carreiras de } \\
\text { especialistas e tecnológicas. Em situações de aprendizagem formal, as pessoas com } \\
\text { esse estilo preferem experimentar novas ideias, simulações, atribuições laboratoriais } \\
\text { e aplicações práticas. }\end{array}$ \\
\hline
\end{tabular}


Quadro 3 - Descrição dos estilos de aprendizagem de David Kolb (Continuação)

\begin{tabular}{|l|l|}
\hline Acomodador & $\begin{array}{l}\text { As pessoas com este estilo de aprendizagem têm a capacidade de aprender com } \\
\text { principalmente a experiência prática Hand-on. Eles gostam de realização de planos } \\
\text { e envolvem-se em experiências novas e desafiadoras. Sua tendência pode estar a } \\
\text { agir em por intuição/emoção em vez da análise lógica. Na resolução de problemas, } \\
\text { aprendizagem } \\
\text { os indivíduos com um estilo de aprendizagem Acomodador dependem mais } \\
\text { dominantes: }\end{array}$ \\
$\begin{array}{l}\text { Experiência } \\
\text { poncreta (EC) e } \\
\text { aprendizagem é importante para a eficácia nas carreiras orientadas para a ação, tais } \\
\text { axperimentação Ativa } \\
\text { (EA) }\end{array}$ & $\begin{array}{l}\text { como marketing ou vendas. Em situações de aprendizagem formal, pessoas com } \\
\text { o estilo de aprendizagem Acomodador preferem trabalhar com os outros para ter } \\
\text { trabalhos realizados, estabelecer metas, fazer trabalho de campo, e testar diferentes } \\
\text { abordagens para concluir um projeto. }\end{array}$ \\
\hline
\end{tabular}

Fonte: Kolb, Boyatzis, Mainemelis (1999, p. 5-7) tradução nossa.

Vale ressaltar que os indivíduos não possuem somente um perfil de aprendizagem. Por ser uma interação, um ciclo de aprendizado, as pessoas têm todos estes estilos em si, porém um é mais destacado.

\subsection{A aprendizagem na Empresa Simulada: O Aprendizado da Decisão}

Segundo Sauaia (2000), os jogos empresariais são utilizados para desenvolver habilidades de gestão, levando os participantes a praticarem a tomada de decisões, a análise de problemas e o controle dos resultados. No estudo feito por este mesmo autor, a maioria dos participantes da simulação empresarial elegeu a disciplina como o tipo de aula que mais Ihe proporcionou aprendizagem, com maior aproveitamento (SAUAIA, 2000). Para Sauaia (2000), essa preferência pode estar relacionada com a dimensão afetivoemocional desencadeada pelo jogo, sendo o participante o elemento ativo de um processo de educação que é vivencial.

A utilização da Empresa Simulada apresenta vários benefícios ao aprendizado quando aproxima o participante da realidade: permite a identificação das consequências progressivas de suas decisões desenvolvendo uma visão de longo prazo, proporciona o pensamento sistêmico e o entendimento da necessidade de integrar as disciplinas, ao perceber que, no mundo real, as decisões estão inter-relacionadas (SILVA; OLIVEIRA; MOTTA, 2013).

Entretanto, Sauaia (2006) afirma que essa ferramenta não auxilia na obtenção de conhecimento teórico e aplicado, devendo ser utilizada como complementar e não como substituta de outras metodologias educacionais (ARBEX, 2005). Sauaia (2000) reconhece que devem ser considerados para o aprendizado nas simulações não somente questões internas do ambiente simulado, mas também aspectos exógenos que influenciam o processo educacional, como o ambiente do treinamento, o perfil dos participantes, a formação das equipes e a complexidade dos jogos.

Mesmo não sendo possível estabelecer precisamente o tipo de relação que existe entre as simulações e o aprendizado, devido aos problemas de medição, é aceito que existe algum relacionamento entre ambos (ANDERSON; LAWTON, 2007). Alguns autores prosseguem com o debate, buscando estabelecer distinções entre o aprendizado percebido (o que os participantes percebem como aprendizado com as simulações) e o aprendizado objetivo (aquilo objetivamente aprendido, explicitado por meio de avaliações conceituais).

\subsubsection{Variáveis intervenientes da aprendizagem em ambientes simulados}

De acordo com alguns autores, como Silva, Oliveira e Motta (2013), os jogos simulados trazem diversos benefícios para o processo de aprendizagem. Porém, segundo Herz e Merz (1998), o indício empírico da contribuição dos jogos simulados em relação à aprendizagem ainda é muito restrito e controverso. Os autores relatam que os resultados contemplam desde avaliações muito positivas do aprendizado até a conclusão de que jogos de simulação contribuem apenas de maneira marginal para o desenvolvimento dos alunos. 
Conseguinte, a qualidade do debriefing se faz crucial para a avaliação daquilo que foi aprendido pelos participantes. Conforme Araújo et al. (2015), o debriefing está relacionado a um instrumento que pode ser coletivo ou individual e oral ou escrito, e que é utilizado com o objetivo de analisar e compartilhar uma ação depois de sua concretização. O autor ainda salienta que na empresa simulada, o debriefing exerce um papel importante com relação ao aprendizado dos envolvidos, pois esta ferramenta possibilita a análise de desenvolvimento de competências como a cooperação, e de aspectos relacionados ao treinamento e à educação. Além do debriefing, há diversas variáveis que podem interferir na aprendizagem por meio de jogos simulados. Estas variáveis estariam relacionadas a três aspectos principais: características dos participantes, do grupo e da simulação. Em cada aspecto está compreendida uma série de fatores envolvidos. A seguir serão discutidos tais fatores.

Por características dos participantes entendem-se os aspectos ligados ao gênero, idade, nacionalidade, estilo de aprendizagem, temperamento, o conhecimento prévio e interesse. Segundo Apesteguia, Azmat e Iriberri (2012), a composição de gênero dos times pode influenciar o desempenho econômico do grupo. O estudo realizado pelos autores demonstrou que esta disparidade de performance ocorre em virtude das diferenças no processo decisório. Os times formados por três mulheres eram menos agressivos em suas estratégias de preço e investiram menos em P\&D e mais em atividades voltadas para aspectos sociais, do que as outras combinações de gênero. No trabalho de Florea et al. (2003) foi constatado também que as mulheres trouxeram abordagens diferenciadas de negociação em relação aos homens, sendo que, quando ambos trabalharam em um grupo misto, o resultado se mostrou distinto.

Outra variável a ser considerada é o conhecimento prévio do aluno. Conforme Wolfe (1985), o fato de haver melhorias no aprendizado dos participantes não implica necessariamente que sejam relativas ao ensino, mas podem significar efeitos relacionados à influência do instrutor ou ao conhecimento prévio dos envolvidos. Portanto, o estudante pode, muitas vezes, incrementar o seu grau de aprendizado em virtude de já possuir um know how anterior ao uso dos jogos simulados.

Como características da simulação considera-se: o grau de interatividade, o simulador utilizado, o ponto de inserção da simulação na grade curricular, a pressão temporal, a complexidade e o tipo de simulação (presencial/remota). Bernard (2006) recomenda grupos de até quatro integrantes, com as tarefas mais bem distribuídas e considerando também as características ligadas aos conjuntos formados pelos alunos, que são: homogeneidade, tamanho e coesão do grupo, por exemplo.

Sobre a coesão do grupo, Araújo et al. (2015) argumentam que a expectativa é que os grupos mais coesos obtenham melhor performance no jogo. Essa coesão não depende do conhecimento anterior entre os participantes, podendo ser desenvolvida ao longo da simulação. Hornaday (2001) estudou a relação entre a coesão do grupo e o sexo de seus integrantes na simulação. O resultado da pesquisa expôs que equipes masculinas têm melhores desempenhos nas simulações e são mais orientadas para a tarefa, enquanto equipes femininas apresentam maiores níveis de comportamento social. Para Hornaday (2001), os desempenhos dos diferentes gêneros dependem da área analisada. Portanto, este conjunto de variáveis apresentado deve ser levado em consideração quando se trata da aprendizagem na empresa simulada, pois diversos fatores internos e externos podem influenciar no processo.

\section{Metodologia da Pesquisa}

Com o intuito de identificar a percepção dos alunos e consultores sobre a disciplina Empresa Simulada em relação à aprendizagem de práticas administrativas, foi utilizada a abordagem de pesquisa qualitativa. Como método de pesquisa adotou-se o estudo de caso de um Centro Educacional Federal. Ressalta-se ainda que a entidade de ensino pesquisada é devidamente credenciada pelo MEC e possui nota 5 no ENADE (Exame Nacional de Desempenho dos Estudantes). A escolha pelo estudo de caso se justifica por atender melhor ao objetivo dessa pesquisa que foi investigar a percepção dos alunos do curso de Administração e dos consultores sobre a contribuição da disciplina Empresa Simulada para a aprendizagem de práticas administrativas. 
Para Yin (2001), o estudo de caso é selecionado como estratégia de pesquisa quando se investiga fenômenos contemporâneos em que os comportamentos relevantes não podem ser manipulados. Além das técnicas empregadas em uma pesquisa histórica, utilizam-se a observação direta e uma série sistemática de entrevistas (YIN, 2001). Dentre as etapas para a realização do estudo de caso, a elaboração de um protocolo possibilita aos pesquisadores analisarem sobre os tópicos que serão estudados e, portanto, aumenta sua confiabilidade. "O protocolo contém o instrumento, mas também contém os procedimentos e as regras gerais que deveriam ser seguidas ao utilizar o instrumento" (YIN, 2001, p. 89).

Dessa forma, o protocolo desse estudo de caso abrange, além do referencial teórico, as técnicas de pesquisa do grupo focal e da observação participante. Segundo Trad (2009, p. 780), o objetivo do grupo focal é "reunir informações detalhadas sobre um tópico específico (sugerido por um pesquisador, coordenador ou moderador do grupo) a partir de um grupo de participantes selecionados". Assim, o grupo focal é um tipo de entrevista em profundidade realizada em grupos que visa obter informações sobre como as pessoas consideram uma experiência, uma ideia ou um evento (OLIVEIRA; FREITAS, 2010). Essa técnica de pesquisa permite a compreensão de atitudes, percepções e crenças a respeito de um tema, serviço ou produto, que é o caso da presente pesquisa (TRAD, 2009).

Para a realização do grupo focal, a turma composta por 16 alunos da graduação em Administração foi dividida em dois grupos de oito alunos para que a discussão pudesse contar com uma maior participação dos integrantes, seguindo a recomendação de Oliveira e Freitas (2010), sobre o grupo focal ter tamanho médio, entre seis a dez pessoas. O grupo focal realizado teve duração de aproximadamente 1 hora e 30 minutos e foi realizado no dia 23 de junho de 2016, ao final. As categorias abordadas no grupo focal envolveram o processo de participação nas seções, como os grupos se organizavam, se utilizavam manuais, planilhas e se consultavam outras pessoas. Também foi discutido sobre como era a tomada de decisão dos grupos, como lidavam com situações de conflitos, e sobre o aprendizado com a Empresa Simulada, qual a contribuição dessa experiência para o aprendizado, quais as dificuldades encontradas, entre outros aspectos que surgiram ao longo das interações entre o grupo.

Já a observação participante ocorreu entre os dias 17 de Março a 16 de Junho de 2016, no horário da disciplina, 19:00h às 20:30h e teve um formato diferenciado - os moderadores eram "consultores" das empresas representadas pelos grupos. Os consultores eram compostos por seis estudantes do curso de Mestrado em Administração da mesma instituição educacional. A partir de elaboração de "diários de bordo", os consultores apresentaram suas impressões com relação ao desempenho dos alunos na dinâmica e esses foram supervisionados pelo professor da disciplina. Nota-se que cada consultor tinha autonomia para intervir ou não durante as rodadas. Esse grau de discricionariedade dado aos consultores pode-se configurar, de acordo com a denominação de Adler e Adler (1987), como uma observação participante ativa em que o investigador opta por desempenhar ou não um papel no grupo, porém mantendo certo distanciamento.

Após a realização do grupo focal, e de maneira complementar, foi aplicado o questionário de Kolb aos alunos presentes no dia 30 de junho de 2016, a fim de realizar uma caracterização dos alunos participantes em relação aos estilos de aprendizagem. O instrumento foi criado por David Kolb (Learning Style Inventory - LSI) em 1976 e no Brasil, foi revisado por Sobral em 1992 (CERQUEIRA, 2008). Para os discentes foi aplicado o formato traduzido e adaptado pelo professor lusitano Luís Aguilar. Essa versão é composta por: "nove séries de palavras, a serem ordenadas pelo estudante em graus de 1 a 4 de acordo, respectivamente, com a menor ou a maior probabilidade de aprendizado percebida por ele" (CERQUEIRA, 2008, p.119). Eis o modelo, como pode ser visto no Quadro 4. 
Quadro 4 - Identificação dos estilos de aprendizagem de David Kolb

\begin{tabular}{|l|l|l|l|l|}
\hline $\mathbf{1}$ & Escolho & Experimento & Envolvo-me & Sou Prático \\
\hline $\mathbf{2}$ & Sou Receptivo & $\begin{array}{l}\text { Esforço-me por ser } \\
\text { Coerente }\end{array}$ & Analiso & Sou Imparcial \\
\hline $\mathbf{3}$ & Sinto & Observo & Penso & Ajo \\
\hline $\mathbf{4}$ & Aceito a Situação & Corro Riscos & Avalio a situação & Presto atenção \\
\hline $\mathbf{5}$ & Utilizo a minha Intuição & Obtenho Resultados & Utilizo a Lógica & Qu estiono \\
\hline $\mathbf{6}$ & Prefiro a Abstracção & Prefiro a Observação & $\begin{array}{l}\text { Prefiro as Coisas } \\
\text { Concretas }\end{array}$ & Prefiro a Ação \\
\hline $\mathbf{7}$ & Vivo o Presente & Reflito & Projecto-me no Futuro & Sou Pragmático \\
\hline $\mathbf{8}$ & $\begin{array}{l}\text { Apoio-me na minha } \\
\text { Experiência }\end{array}$ & Observo & Conceptualizo & Experimento \\
\hline $\mathbf{9}$ & Concentro- me & Sou Reservado & Racionalizo & Responsabilizo- me \\
\hline & EC $\mathbf{2 , 3 , 4 , 5 , 7 , 8}$ & OR 1,3,6,7,8,9 & CA 2,3,4,5,8,9 & EA 1,3,6,7,8,9 \\
\hline
\end{tabular}

Fonte: Kolb (1984). Adaptado por Aguilar (2000).

Em seguida, os alunos realizaram o somatório das respostas dos números indicados na parte inferior da Tabela. A identificação do estilo de aprendizagem ocorre pela construção de um gráfico (Figura 1), com a sinalização da pontuação obtida nas quatro habilidades nos quadrantes e posteriormente pela marcação no gráfico, como se fossem pares ordenados. A imagem obtida no círculo próxima aos 100 por cento representam o estilo de aprendizagem mais sobressalente daquele aluno.

Em todas as técnicas de pesquisas escolhidas foram considerados os 16 alunos matriculados na disciplina "Empresa Simulada" do curso de graduação em Administração de um Centro Educacional Federal. Ressalta-se que para essa disciplina, os alunos utilizaram o software Bernard Simulação Industrial, versão Sind 7.0, de Florianópolis. Além disso, eram emitidos relatórios com a análise do professor e também um jornal virtual (Boletim de Notícias) para o acompanhamento diário dos alunos.

Como suporte para o estudo de caso e atendendo ao objetivo geral dessa pesquisa qualitativa dentro do campo da Administração, a análise de conteúdo segundo Bardin (2011) é dividida em três etapas: préanálise, exploração do material e tratamento dos resultados. Assim, de acordo com o referencial teórico apresentado e do conteúdo gerado pelos grupos focais foram elencadas as seguintes categorias: o papel do consultor; perspectivas de aprendizagem; simulação x realidade; o momento da disciplina; estilos de aprendizagem e o aprendizado das práticas. Essas categorias serviram também para nortear a análise e discussão dos resultados.

\section{Resultados e Discussão}

\subsection{Aspectos demográficos e o papel dos consultores}

Com relação à demografia, observou-se que, de um total de 16 alunos matriculados na disciplina Empresa Simulada, cinco eram homens e onze mulheres. A idade dos membros ficou concentrada na faixa etária entre 19 a 24 anos, com uma média de 21,6 anos. Além disso, o grupo focal contou com uma amostra de 15 pessoas, sendo uma aluna faltante e o questionário de Kolb foi aplicado para 11 alunos, visto que um aluno e três alunas estavam ausentes na data da aplicação do mesmo. Com relação à composição das "empresas", observou-se que três dos quatro grupos foram formados pela configuração de três mulheres e um homem em cada. Apenas uma empresa foi composta por duas mulheres e dois homens (Empresa C), o que pode ter influenciado o resultado positivo obtido por esta empresa em diversas rodadas. De acordo com um dos consultores: "Todos demonstram ser competitivos, mas as meninas são mais conservadoras e tem mais medo de arriscar do que os meninos".

O que confirma o que Apesteguia, Azmat e Iriberri (2012) já atentaram para a influência da composição do gênero sobre o desempenho econômico do grupo, e que quando o grupo é misto, o resultado se distingue dos demais. 
O grupo de consultores era composto de seis mulheres e dois homens, todos eram alunos do mestrado em Administração. Uma das consultoras permaneceu durante toda a disciplina com o mesmo grupo. Ela justificou que optou por ficar com o mesmo grupo, pois queria observar como seria a ligação do grupo com ela. Os demais consultores escolheram fazer um rodízio entre os grupos, acompanhando um grupo diferente a cada rodada. A justificativa dessa escolha é que queriam comparar a percepção em diferentes grupos.

Alguns consultores sentiam que sua participação não fazia diferença para os grupos. Outros reclamaram que os alunos não queriam escutar seus conselhos. Uma consultora afirmou que chegou a utilizar a proximidade com o professor da disciplina para ser ouvida pelo grupo, como se tivesse informações privilegiadas. Um dos consultores afirmou que para os alunos da graduação, os consultores eram "estranhos e espiões do professor".

As consultoras que se envolveram mais com os grupos discordaram desse aspecto. Uma delas afirmou ainda que mesmo em dias que não era obrigada a acompanhar o grupo ela participava.

No grupo focal realizado com os consultores eles ainda classificaram os grupos dos alunos da graduação da seguinte forma: os centralizadores, as ansiosas, a panelinha e os desmotivados.

Em relação ao papel do consultor, os consultores afirmaram, durante o grupo focal, que sentiam dificuldades em estabelecer os limites entre o executar e o aconselhar. Alguns mudaram a postura no decorrer das rodadas, adotando um papel mais distante. Eles optavam por não assumir posições incisivas para não se frustrarem, e por uma questão de responsabilidade sobre os resultados, que deveria estar sobre o grupo e não sobre os consultores.

\subsection{Perspectivas de aprendizagem}

Na realização do grupo focal com os alunos da graduação, foram destacadas algumas habilidades que eles desenvolveram ao longo do semestre enquanto estavam cursando a disciplina Empresa Simulada. Dentre estas, a mais citada foi o trabalho em equipe e o relacionamento com os membros do grupo. Os alunos destacaram que a disciplina possibilitou o entendimento de que as próprias ações não podem ser executadas de forma individual, pois existe uma interdependência relacionada às ações dos colegas de trabalho. Este resultado reforça a afirmação de Motta e Armond-de-Melo (2008) de que a interação pessoal entre os alunos é o ponto forte da simulação. O jogo traz a necessidade de trabalhar em equipe e, assim a competência humana é desenvolvida. Relacionado a isso, a percepção dos consultores é que alguns alunos não conseguiam participar em alguns grupos, conforme relato de um dos consultores:

De quatro participantes, apenas 3 participavam. Uma quarta integrante não falava nada. Entre os 3 que participavam, a relação era boa, amistosa e leve. Não havia um líder definido, os 3 participavam de maneira semelhante.

Com a rodada de demissão, em que cada grupo deveria demitir um dos integrantes, houve uma mudança na dinâmica dos grupos, já que esses mesmos alunos conseguiam participar de forma mais ativa nos grupos receptores. Uma justificativa para esse fato, de acordo com os consultores é que como os grupos foram escolhidos pelos próprios alunos, a relação de amizade entre alguns acabava isolando outros.

Além das habilidades cognitivas analisadas, os alunos também apresentaram mudanças comportamentais devido a essa interação interpessoal. Atitudes como competitividade e afetividade foram percebidas durante a disciplina. Tais modificações no comportamento também foram identificadas nos estudos de Dutra e Sauaia (2007) cujos participantes dos laboratórios de gestão empresarial se envolveram em práticas de cooperação ilícitas, como a formação de máfias, por motivações exclusivamente afetivas. Esse desenvolvimento da afetividade foi percebida não só entre alunos, mas também entre alunos e consultores, já que alguns grupos tinham preferência por determinados consultores.

Outra habilidade apontada foi o desenvolvimento do pensamento estratégico citado como um aprendizado importante com relação à utilização dos jogos simulados. Nesse sentido, um dos alunos 
ressaltou a importância deste pensamento bem definido, afirmando que seu grupo adotou a estratégia de arriscar e que esta foi positiva, de forma a representar um diferencial em relação às outras empresas:

$\mathrm{Na}$ primeira rodada todas as empresas estavam iguais, aí eu acho que a nossa empresa foi a que mais arriscou porque a gente vendeu as máquinas que a gente tinha e comprou uma máquina com capacidade maior. E aí nessa rodada a gente assumiu o primeiro lugar e aí o ponto de partida foi marcante porque foi a estratégia que no momento só a gente tinha feito (Aluno, Empresa C).

A percepção dos alunos condiz com a afirmativa de Nagamatsu, Fedichina e Gozzi (2006) de que o estudante, ao lidar com os jogos simulados, tem a oportunidade de participar de simulações relacionadas à tomada de decisões.

Portanto, os depoimentos dos alunos no grupo focal estão alinhados ao que Sauaia $(2000,2006)$ acredita: que a empresa simulada tenha uma boa aceitação por parte dos alunos por ser mais dinâmica e retira os estudantes das tradicionais aulas expositivas, dando a eles o poder da decisão, bem como a responsabilidade sobre as consequências dessas decisões.

\subsection{Simulação x Realidade}

A discussão da aproximação da simulação à realidade esteve presente durante toda a realização do grupo focal. Em geral, os relatos dos alunos demonstraram uma boa receptividade com a ferramenta de Empresa Simulada, indicando que diversas situações puderam ser vivenciadas como na prática. Mesmo sendo relatado pelos consultores que nas rodadas iniciais, os alunos tiveram muita dificuldade em mexer no sistema. Os estudantes afirmaram que a Empresa Simulada trouxe um pouco do conhecimento adquirido em sala de aula pelas teorias para a prática:

Muitos dados a gente percebeu que tem que andar lado a lado, como a questão do preço que tinha que estar alinhado com a questão da propaganda, de forma a fazer uma combinação. Então eu acho que foi bem legal, foi bem dinâmico e deu pra explorar e colocar um pouco da teoria que a gente tem no nosso curso um pouquinho na prática. E deu pra gente aplicar muitas coisas que provavelmente funcionam igual na empresa simulada (Aluno, Empresa C).

A vivência da prática relatada pelos alunos coaduna as afirmações de Rodrigues e Souza (2001) de que a simulação tem o intuito de reproduzir o ambiente e o comportamento do mercado de trabalho, experiência que os estudantes provavelmente não teriam acesso antes de se formarem.

Houve o relato também de situações em que houve muita competitividade entre os alunos. Um aluno destacou que em certo momento, as decisões tomadas eram todas voltadas para atingir as empresas adversárias. Eles disseram que aprenderam que esta era uma estratégia que os ajudaria a obter mais ganhos. Este tipo de comportamento também pode ser observado no mercado de trabalho real, em que as empresas buscam vantagens competitivas, com o intuito de se destacarem perante as outras. Pelo relato dos alunos foi possível enxergar as cinco etapas da aprendizagem vivencial, descrita por Baraúna e Montalvo (2012). Eles perceberam na vivência, com a experiência concretizada, o que traria benefícios em relação aos outros grupos, compartilharam a ideia e aplicaram na prática da simulação.

Alguns alunos ressaltaram que o simulador limitou um pouco a experiência da simulação, uma vez que a realidade permite a adoção de determinadas alternativas que não podiam ser alteradas pelo software utilizado, como por exemplo, para minimizar custos.

Uma coisa que nós reparamos também é a questão da realidade ter diferenciais dentro das empresas, que o simulador não permite. Por exemplo, a logística interna conta muito. Porque hoje em dia você consegue comprar uma máquina pela internet. Uma máquina industrial mesmo. [...] Como o simulador tem essa questão do algoritmo, de ser mais engessado assim, ele não permite que a gente trabalhe essas coisas.

Nesse sentido, fica evidenciado que as características da simulação interferem diretamente na aprendizagem dos jogos simulados, conforme mencionado por Araújo et al. (2015). Portanto, para os 
alunos, o simulador utilizado poderia possuir mais opções com relação às ferramentas de decisão para possibilitar a visão de alternativas para maximizar o negócio.

Se a empresa real fosse só essas coisas (da empresa simulada) pra gente preencher seria mais fácil. A gente vê que na vida real tem muitas outras coisas que envolvem (uma empresa), como motivação, o salário, participação, treinamentos. [...] A questão é que era tudo nivelado [...] assim como as máquinas que não tinham uma diferenciação. [...] O simulador tem poucas variáveis (Aluno, Empresa C).

Segundo Silva, Oliveira e Motta (2013) e ainda Sauaia (2000) essa é a importância da simulação, a noção de responsabilidade sobre as decisões e consequências. No depoimento, o aluno demonstra ter compreendido que quando se deparar com a realidade, as decisões serão mais complexas do que no jogo, já que no mundo real existem outras variáveis não agregadas pelo simulador. Nos depoimentos percebeuse um anseio por maior aproximação da realidade.

\subsection{Momento da disciplina}

Quando indagados sobre o momento da aplicação da Empresa Simulada no curso, muitos alunos opinaram que estariam mais preparados para ter a disciplina ao final do curso e não no $5^{\circ}$ (quinto) período como ocorre. Eles ainda sugeriram que o $7^{\circ}$ (sétimo) período seria ideal, pois já teriam tido várias disciplinas relacionadas à administração da produção e sobre finanças, que os ajudariam a tomar a decisão com mais firmeza. Tal dificuldade é identificada por Motta e Armond-de-Melo (2008) como um desafio, pois a Empresa Simulada necessita de grande interação multidisciplinar e no $5^{\circ}$ (quinto) período os alunos ainda não tiveram algumas disciplinas que são essenciais para a tomada de decisão no jogo. $O$ relato de uma das consultoras demonstra essa dificuldade:

Dei a ideia para elas começarem calculando o ponto de equilíbrio da produção [...] não sabiam sobre este conceito e pesquisaram na hora. O cálculo não deu certo, viram que tinham que estudar mais e decidiram fazer no "chutomêtro".

Wolfe (1985) também salienta que a aprendizagem pode apresentar melhorias em virtude da influência do instrutor ou do conhecimento prévio dos envolvidos. Assim, os alunos se interessavam pela formação dos consultores, conforme relato de uma das consultoras:

Um exemplo dessa situação foi quando me indagaram qual área da administração eu era. Respondi que não era formada em administração, mas sim em Relações Internacionais e Gestão Pública. Percebi que o semblante do grupo alterou.

Por outro lado, alguns alunos acharam interessante ter essa disciplina nesse momento do curso para despertar o interesse de aprender sobre novos conhecimentos: "Hoje eu acho interessante ter a empresa simulada bem assim na metade (do curso), por que aí você também corre atrás dos conhecimentos que a gente não tem" (Aluna, Empresa A). Por meio da empresa simulada foi possível ter um contato inicial com certos conteúdos. Os alunos destacaram ainda que por mais que não soubessem determinados assuntos, eles tentavam descobrir como "funcionava" para que a decisão fosse a mais adequada possível: "Eu acho que desperta o interesse, porque ainda que não tenha base teórica, fica gostoso a gente não saber, mas querer saber para tomar a decisão certa" (Aluna, Empresa B).

Com o desenvolvimento da discussão no grupo focal, eles chegaram a um acordo que o ideal seria ter a disciplina Empresa Simulada em dois momentos: no $5^{\circ}$ (quinto) período e no final do curso para que pudesse ser avaliada a evolução dos alunos. Eles ainda sugeriram que no final do curso poderia ser utilizado um software com uma aproximação maior da realidade.

\subsection{Estilos de aprendizagem e o aprendizado das práticas}

A turma de alunos analisada apresentou a predominância de dois perfis de aprendizagem - o divergente e o assimilador. Isso demonstra que há um equilíbrio entre esses estudantes de estilos de aprendizagem que aprendem na prática vivenciada e na teoria. Contudo, deve-se ressaltar que na amostra 
teve alunos que demonstraram forte equivalência entre dois estilos de aprendizagem. Em virtude disto, houve uma duplicidade na contagem. Esses resultados não invalidam a análise haja vista que Kolb (1984) menciona que os indivíduos apresentam em si todos os estilos de aprendizagem, porém algum prevalece mais.

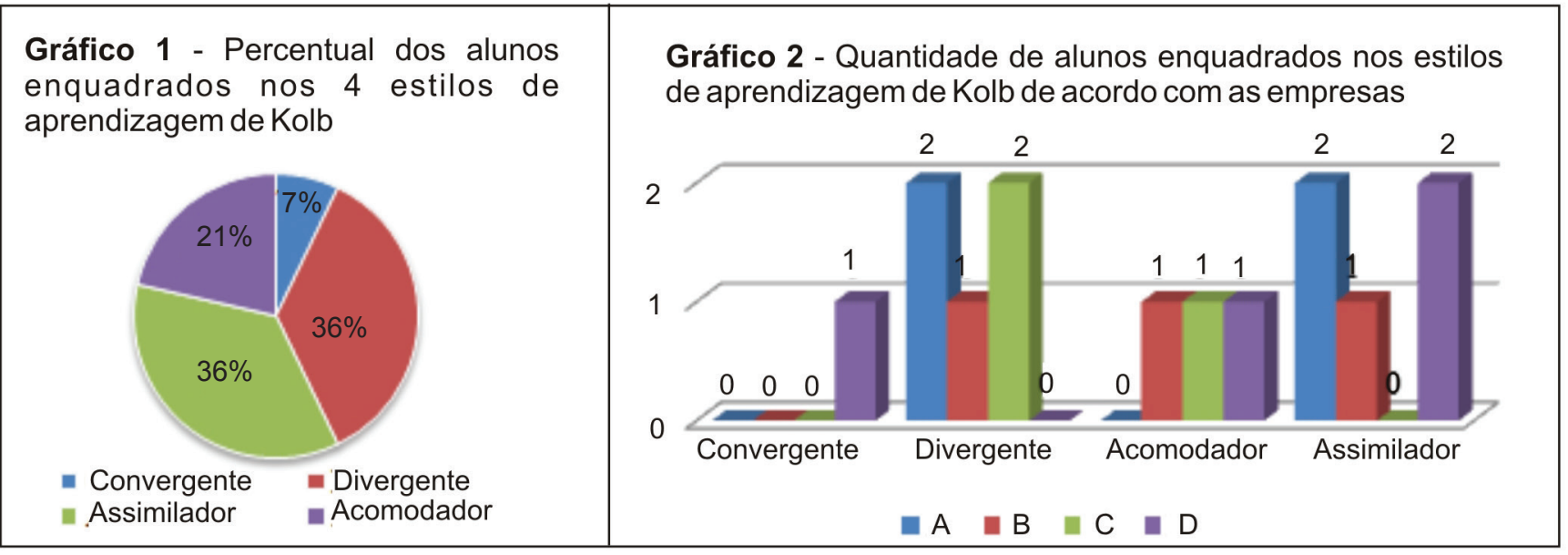

Fonte: Elaborado pelos autores

Os dados de perfis de aprendizagem dos alunos também foram analisados separadamente, distinguindo as empresas em que atuaram. Vide Gráfico 2. Nota-se que o perfil 'convergente' apenas apareceu na empresa D. Isso indica que entre os alunos, tal estudante é uma exceção, que conforme Kolb, Boyatzis e Mainemelis (1999), representa um perfil que prefere lidar com tarefas técnicas e problemas, em vez de com as questões sociais e questões interpessoais. Por isso, a empresa $D$ possui uma grande diversidade de estilos na empresa simulada. Contudo, não houve estudante com o perfil divergente nessa empresa (um dos predominantes da amostra), ou seja, pessoas cujo estilo de aprendizagem é mais sensorial e tendem a ser mais imaginativas. Indivíduos com o perfil divergente de aprendizado são mais propensos a trabalhar em grupo e são mais receptivos e abertos a críticas. Pela observação participante, constata-se que os participantes desta empresa possuíam opiniões contrárias e facilmente entravam em conflitos, o que reflete a ausência do perfil divergente na empresa.

No entanto, o estilo de aprendizagem divergente é evidente nas empresas A e C, cujo desempenho da disciplina está entre os melhores: a empresa $C$ permaneceu em primeiro lugar por várias semanas e a empresa A finalizou em alta, com o pódio. Já a empresa B não obteve bons resultados e consta também uma variedade nos estilos de aprendizagem. O estilo assimilador refere-se ao perfil de aprendizado voltado para a observação e para a reflexão. Os estudantes desse estilo são mais observadores e pensam mais antes de tomarem uma decisão. Tal situação é corroborada com as informações da observação participante, pois os alunos das empresas $A$ e $D$ demonstraram esse perfil. $O$ estilo acomodador é considerado um aprendizado mais intuitivo, isto é, pessoas que são guiadas mais pela intuição em vez da lógica. Todas as empresas possuem algum membro com esse perfil de aprendizagem, exceto a empresa $A$, ganhadora da simulação industrial.

Por meio da observação dos consultores, foi possível compreender que no grupo A, o equilíbrio entre os perfis assimilador e divergente contribuiu para um resultado positivo, já que as características positivas de um compensam as negativas de outro, por exemplo, o perfil divergente tem maior facilidade de relacionamento com pessoas e trabalhar em grupo, além de serem mais criativos. No caso do perfil assimilador, as pessoas tem maior facilidade em trabalhar com muitas informações, que é o caso da empresa simulada, e com raciocínio lógico, buscando se basear em teorias e modelos para compreenderem os assuntos. Este equilíbrio reitera a proposição de Kolb (1984), de que são necessárias quatro habilidades básicas para que seu aprendizado seja efetivo.

Com relação os membros da empresa $\mathrm{C}$ cuja maioria dos membros apresentou o perfil divergente, o qual é mais relacionado às atividades práticas, o consultor que acompanhou o grupo afirmou que 
houve preocupação em consultar os meios disponíveis para embasar as suas escolhas: arquivos e documentos do gerados pelo simulado, as observações do professor, o gazeta, bem como investigar as possibilidades reais de adoção de determinadas práticas. Como se pode perceber no relato do consultor que acompanhou a Empresa C, a simulação trouxe ao grupo a necessidade de buscar um aporte teórico que auxiliasse nas decisões. Esse grupo não tinha nenhum aluno com estilo predominante de assimilador, o que talvez facilitaria essa busca pelo aporte, que ocorreria naturalmente com esse estilo. A simulação envolve disciplinas ainda não aprendidas no curso, e isso fez com que os alunos aprendessem na prática, observando pelas consequências de suas decisões, como deveriam agir (SAUAIA, 2000).

Não foi possível fazer um paralelo entre os estilos de aprendizagem e a aprendizagem efetivamente, pois os grupos eram heterogêneos e não houve como medir o aprendizado de cada um relacionando ao seu estilo. Entretanto, foi possível foi observar pelo olhar dos consultores que certos estilos, como o divergente possui maior facilidade de trabalhar em grupos e essa característica foi importante para obterem os melhores resultados no jogo simulado.

O aprendizado das práticas ocorreu interativamente quando os alunos de maneira por pró-ativa buscaram pelo conhecimento que ainda não possuíam para a concretização das atividades da Empresa Simulada, bem como pelo auxílio dos consultores que optaram por compartilhar os conhecimentos que possuíam com os graduandos. Este resultado corrobora com Silva, Oliveira e Motta (2013), que afirmam que o aprendizado das práticas parte do indivíduo aluno, que é ativo no processo de construção do conhecimento. Portanto, a empresa simulada, é uma forma de o aluno partir da prática para a teoria, inverso do que ocorre nas disciplinas tradicionais. É a descoberta que conduz ao aprendizado por meio do envolvimento do aluno. (SILVA; OLIVEIRA; MOTTA, 2013).

\section{Conclusão}

É fato que cada indivíduo aprende de uma forma singular. Essa diversidade justifica os vários estudos relacionados à aprendizagem, sem jamais cessar os debates. Os estudos de Kolb (1984) revelam que a aprendizagem ocorre em um ciclo que envolve experiências, sentimentos, observação e atitudes. O questionário proposto por ele ressalta que cada indivíduo possui maior incidência de um estilo de aprendizagem, o que pôde ser percebido pela observação participante durante as tomadas de decisões em diferentes grupos.

$\mathrm{Na}$ turma analisada, houve um equilíbrio entre os estilos assimilador e divergente e percebeu-se que pela explicação de Kolb (1984), os dois estilos localizam-se em quadrantes diferentes. Enquanto o assimilador busca a lógica em detrimento do relacionamento interpessoal, o divergente tem mais facilidade em trabalhar em equipe e é mais propenso a aceitar as opiniões alheias. Conforme os relatos, a percepção dos alunos em relação ao aprendizado com a disciplina está relacionada ao trabalho em equipe, o que pode ser considerado um ponto a ser desenvolvido, já que grande parte da turma tem o estilo assimilador. Esse estilo, segundo Kolb (1984), refere-se a um estilo de aprendizagem mais introspectivo.

A expectativa em se aproximar da realidade com a disciplina foi percebida com algumas críticas pelos alunos, pois segundo eles, o software é simplificado e limitado. Em relação ao momento da disciplina, os alunos relataram no grupo focal que o ideal seria coloca-la ao final do curso, pois já teriam uma base teórica mais bem preparada para tomar as decisões. Entretanto, analisando a Empresa Simulada como uma disciplina complementar tal como sugere Arbex (2005), e por não trazer um conhecimento teórico e aplicado, como justificado por Sauaia (2006), o momento em que foi aplicada (5ºríodo) é interessante como uma forma de despertar o interesse dos alunos em aprender outras disciplinas e de demonstrar a importância da interdependência entre as disciplinas para a realidade organizacional.

A realização dos grupos focais foi importante não só para os pesquisadores, como também para os alunos e consultores, por proporcionar um momento de troca de experiências por meio dos relatos. Essa troca de experiências é uma etapa do processo de aprendizagem vivencial conforme Baraúna e Montalvo (2012). Adicionalmente, a observação participante diferenciada via "consultores" mestrandos em Administração possibilitou o aprendizado das práticas pelo compartilhamento de conhecimentos. Alguns 
dos alunos de mestrados já atuaram no mercado laboral e eram especialistas em determinadas áreas (finanças, marketing), o que possibilita que o aprendizado resulte também pelo contato interativo entre os alunos de mestrado e de graduação.

O estudo realizado apresenta uma limitação relacionada à metodologia escolhida, visto que o estudo de caso dificulta as generalizações dos resultados em virtude de contemplar uma situação específica e singular. Logo, há uma impossibilidade de generalizações para outras simulações e mesmo para outras turmas. Houve também a dificuldade em mensurar o aprendizado dos alunos, outra limitação do trabalho. Todavia, a importância do artigo está em vislumbrar sobre a relevância da empresa simulada para o aprendizado no ambiente acadêmico, partindo das percepções dos alunos. Além de dar aos alunos o poder das decisões, a ferramenta os envolve num ambiente próximo da realidade, desenvolve habilidades como o pensamento sistêmico, o trabalho em equipe e o gerenciamento de riscos.

O presente trabalho ainda corrobora com alguns dos resultados encontrados por Araújo et al. (2015) realizado entre 2011 e 2013. Nesse estudo, os resultados encontrados relacionados à aprendizagem foram considerados satisfatórios em relação à percepção dos estudantes. Porém, esse mesmo trabalho também evidenciou que a percepção e o desempenho do aluno não guardavam nenhuma relação com o seu estilo de aprendizagem, o que não foi constatado na presente pesquisa. No estudo atual, o estilo divergente é evidente nas empresas A e C, cujo desempenho da disciplina está entre os melhores. Tal diferença de resultado pode estar no método utilizado (agora qualitativo) frente a um estudo anterior, quantitativo, que talvez não tenha tido acuidade suficiente para encontrar alguma relação significativa entre percepção da simulação e estilo de aprendizagem do praticante.

Para estudos futuros, é sugerida uma análise mais aprofundada da aprendizagem em simulação, evidenciando aspectos como gênero e idade. Outra sugestão é alterar o setor da simulação. Analisar se o interesse anterior do aluno - seja comercial, financeiro, industrial - influencia no desempenho na simulação, já que possui um estímulo interno que o faça buscar um máximo de aproveitamento, visando sua atuação futura no mercado de trabalho.

\section{Referências}

ADLER, P.; ADLER, P. Membership Roles in Field Research. New York: Sage, 1987.

AGUILAR, L. Estilo individual de aprendizagem. In: Manual de Comunic-Acção para o Ensino do Português, Língua Estrangeira. 2000. Disponível em: <http://migre.me/uZZZL>. Acesso em 20 de jun. 2016.

APESTEGUIA, J.; AZMAT, G.; IRIBERRI, N. The impact of gender composition on team performance and decision-making: evidence from the field. Management Science, Catonsville, v. 58, n.1, p. 78- 93, 2012.

ANDERSON, P. H.; LAWTON, L. Simulation performance and its effectiveness as a PBL problem: a follow-up study. Developments in Business Simulation and Experiential Learning, Oklahoma, v. 34, p. 43-50, 2007.

ARAÚJO, U. P.; BRITO, M. J.; CORREIA, L. F.; PAIVA, F. D.; SANTOS, A. O. Simulação de Negócios no Ensino da Administração em Centro de Educação Brasileiro. Revista Electrónica Iberoamericana sobre Calidad, Eficacia y Cambio en Educación, v. 13, n. 2, p. 99-130, 2015.

ARBEX, M. A. O valor pedagógico dos jogos de empresas na aprendizagem de gestão de negócios. Revista FAE, Curitiba, v. 8, n. 2, p. 81-89, 2005.

BARAÚNA, S. M.; MONTALVO, M. R. B. S. Novas abordagens de ensino e aprendizagem: possibilidades de inovação no ensino superior. Comunicações, Piracicaba, v. 9, n. 1, p. 182-197, 2012.

BARDIN, L. Análise de conteúdo. São Paulo: Edições 70, 2011.

BERNARD, R. Estrutura de utilização dos jogos de empresas nos cursos de graduação em administração e ciências contábeis do país e avaliações preliminares de uma disciplina baseada neste 
método. In: XVII ENANGRAD, 17., 2006, São Luis. Anais... São Luis, 2006.

BORDENAVE, J. D.; PEREIRA, A. M. Estratégias de ensino-aprendizagem. 2 ed. Petrópolis: Horizontes Pedagógicos, 2006. 152 p.

CERQUEIRA, T. C. S. Estilos de aprendizagem em universitários. 2000. 179 f. Tese (Doutorado em Educação). Faculdade de Educação da Universidade Estadual de Campinas, São Paulo, 2000.

CERQUEIRA, T. C. S. Estilos de Aprendizagem de Kolb e sua Importância na Educação. Revista de Estilos de Aprendizagem, Madrid, v. 1, n. 1, p. 109-123, 2008.

DUTRA, I. S.; SAUAIA, A. C. A. Alianças em rede de empresas no laboratório de gestão empresarial. Revista Ciências Administrativas, Fortaleza, v. 13, n. 2, p. 317-327, 2007.

FARIA, A. J. The changing nature of simulation research: a brief absel history. Developments in Business Simulation and Experiential Learning, Oklahoma, v. 27, p. 84-90, 2000.

FELDER, R. M.; SILVERMAN, L. K. Learning and teaching styles in engineering education. Engineering education. Raleigh, v. 78, n. 7, p. 674-681, 1988.

FLOREA, N. B.; BOYER, M. A.; BROWN, S. W.; BUTLER, M. J.; HERNANDEZ, M.; WEIR, K.; MENG, L.; JOHNSON, P. R.; LIMA, C.; MAYALL, H. J. Negotiating from Mars to Venus: gender in simulated international negotiations. Simulation \& Gaming, Thousand Oaks, v. 34, n. 2, 226-248, 2003.

HERZ, B.; MERZ, W. Experiential Learning and the Effectiveness of Economic Simulation Games. Simulation \& Gaming, Thousand Oaks, v. 29, n. 2, p. 238-250, 1998.

HORNADAY, R. W. Sex composition, cohesion, consensus, potency and performance of simulation teams. Developments in Business Simulation and Experiential Learning, Oklahoma City, v. 28, p. 102-105, 2001.

KOLB, D. A. Experimental Learning: experience as the source of learning and development. Englewood Cliffs: Prentice-Hall, 1984. 256 p.

KOLB, D. A.; BOYATZIS, R. E.; MAINEMELIS, C. Experiential Learning Theory: Previous Research and New Directions. Working Paper Series. Cleveland, v. 1, p. 1-40, 1999.

MOTTA, G.; ARMOND-DE-MELO, D. R. A prática da aprendizagem baseada em problemas nos cursos de gestão. In: Colóquio Internacional sobre Ensino Superior, 1., 2008, Santana. Anais...Santana, 2008.

MOTTA, G. S.; ARMOND-DE-MELO, D. R.; PAIXÃO, R. B. O jogo de empresas no processo de aprendizagem em administração: o discurso coletivo de alunos. RAC-Revista de Administração Contemporânea, Rio de Janeiro, v. 16, n. 3, p. 342-359, 2012.

NAGAMATSU, F. A.; FEDICHINA, M. A. H.; GOZZI, S.; BOLDRIN, V. P. A aplicação do jogo de empresas no desenvolvimento gerencial: um estudo aplicado em cursos de graduação e de pós-graduação (nível lato sensu). In: Seminários de Administração (SEMEAD), 9., 2006, São Paulo. Anais...São Paulo: FEAUSP, 2006.

OLIVEIRA, D. E. de. Impacto dos estilos de aprendizagem no desempenho acadêmico do ensino de Contabilidade: uma análise dos estudantes da Universidade Federal do Rio Grande do Norte. 2012. 107 f. Dissertação (Mestrado em Ciências Contábeis). Programa Multi-institucional e Inter-Regional de Pós-Graduação em Ciências Contábeis UnB/UFPB/UFRN, Natal, 2012.

OLIVEIRA, M.; FREITAS, H. Focus Group: instrumentalizando o seu planejamento. In: SILVA, A. B.; GODOI, C. K.; BANDEIRA-DE-MELO, R. (Orgs) Pesquisa Qualitativa em Estudos Organizacionais: paradigmas, estratégias e métodos. 2. ed. São Paulo: Saraiva, 2010.

RODRIGUES, J. S.; SOUZA, Z. J. de. Jogos de empresas como ambiente de aprendizado. Revista de Ensino de Engenharia, Brasília, v. 28, n. 2, 2010. 
ROSAS, A. R., SAUAIA, A. C. A. Modelo conceitual de decisões no estágio de criação de um negócio: base para construção de um simulador para jogos de empresas. Revista de Administração Contemporânea, Curitiba, v. 13, n. 4, p. 663-682, 2009.

SANTOS, M. S.; ANDRADE, M. A. R.; ROMÃO, L. S. GONÇALVES, M. A. Teoria dos Jogos Empresariais como Estratégia de Ensino Aprendizagem nos Cursos de Administração de Empresas. Revista Práxis, Volta Redonda, v. 6, n. 12, p. 117-129, 2014.

SAUAIA, A. C. A. Satisfação e aprendizagem em jogos de empresas: contribuições para a educação gerencial. 1995. 273 f. Tese (Doutorado em Finanças e Marketing) - Faculdade de Economia, Administração e Contabilidade, Universidade de São Paulo, São Paulo, 1995.

SAUAIA, A. C. A. Conhecimento Versus Desempenho das Organizações: Um Estudo Empírico com Jogos de Empresas. Revista Eletrônica de Administração, Porto Alegre, v. 12, n. 1, p. 1-17, 2006.

SAUAIA, A. C. A. Laboratório de Gestão: Simulador Organizacional, Jogo de Empresas e Pesquisa Aplicada. 2.ed. Barueri: Manole, 2010. 296 p.

SILVA, S. S.; OLIVEIRA, M. A.; MOTTA, G. S. Jogos de empresas e método do caso: contribuições ao processo de ensino e aprendizagem em administração. Administração: Ensino e Pesquisa, Rio de Janeiro, v. 14, n. 4, p. 677-705, 2013.

TRAD, L. A. B. Grupos focais: conceitos, procedimentos e reflexões baseadas em experiências com o uso da técnica em pesquisas de saúde. Physis - Revista de Saúde Coletiva, Rio de Janeiro, v. 19, n. 3, p. 777-796, 2009.

WOLFE, J. The teaching effectiveness of games in collegiate business courses. Simulation \& Gaming, Thousand Oaks, v. 16, n. 3, p. 251-288, 1985.

YIN, R. K. Estudo de Caso: planejamento e método. 2 ed. Porto Alegre: Bookman, 2001.

Submetido em: $25 / 08 / 2016$

Aprovado em: 26/12/2017 